\title{
Design of Curved Slot and Parasitic Patch Ultra-Wide Bandwidth Antenna for $\mathrm{C}$ and X-Band Applications
}

\author{
Mahima.V. B ${ }^{1}$, Sabapathi. $T^{2}$ \\ ${ }^{1}$ PG Scholar, Department of ECE, Mepco Schlenk Engineering College, Sivakasi, India \\ ${ }^{2}$ Associate Professor, Department of ECE, Mepco Schlenk Engineering College, Sivakasi, India
}

\begin{abstract}
The demand for wireless wideband communications is rapidly increasing due to the need to support more users and to provide more information at higher data rates. Recently, UltraWideband (UWB) technology has been used in reliable communication for transmitting data within a short range of frequencies. The objective of the project is to design, simulate, fabricate, and analyze a compact size ultra-wideband microstrip patch antenna designed at a frequency of $8.6 \mathrm{GHz}$. To provide ultra-wide bandwidth, the antenna is designed using eight parasitic patches and a curved patch with a curved slot, and the ground is made partial. With the help of the parasitic patch, wide bandwidth characteristics can be achieved. FR4 (FlameRetardant4) is used as the substrate. The simulation was performed in ANSYS HFSS software. The designed antenna can cover both $\mathrm{C}$-band ( 4 to $8 \mathrm{GHz}$ ) and $\mathrm{X}$-band $(8$ to $12 \mathrm{GHz}$ ) applications.
\end{abstract}

Index terms -- Parasitic patch, Ultra Wide Bandwidth, Return loss, Radiation pattern, Gain, HFSS

\section{INTRODUCTION}

Ultra-Wideband (UWB) is an ultra-low power technology that transmits a high amount of data over a short distance. The term "wideband" means that the bandwidth significantly exceeds the coherence bandwidth of the channel. It uses no fixed frequency and can transmit data over wide range of frequencies. UWB corresponds to a wide bandwidth atleast greater than $500 \mathrm{MHz}$ (or) the fractional bandwidth should be greater than 20 percent of critical frequency $\left(f_{C}\right)$. The UWB standard is IEEE 802.15.4a and the data rate is about 1 Gbps. Data transmission using UWB is safe and secure. The main characteristics of UWB are high precision, high transmission speed, and reliability. The UWB is much better when compared to wi-fi, bluetooth, and optical communication due to its reliability, cost efficiency, scalability, and safety. UWB is used in short range wireless applications, target sensor data collection, home automation, automobile detection systems, tracking applications, precision locating, medical ranging, real time location systems[1].

An antenna is an electrical device which transmits and receives signals. It converts electrical power into radio waves, and vice versa. There are many types of antenna; one such is a microstrip patch antenna which consists of a radiating patch(es) on one side and has a ground plane on another side. The patch acts as a resonant cavity (short-circuit at top and bottom, and open-circuit at the sides). If the antenna is excited at a resonant frequency, a strong field will set up inside the cavity and a strong current on the bottom surface of the patch which results in significant radiation. Some advantages of using microstrip patch antenna are it has light weight; ease of installation and low cost [2]. The microstrip patch antenna can be used in low profile applications, space craft applications, etc. In mobile, small, low cost, low profile antennas are used. Atleast one antenna will be present in mobile phones. These antennas will be used for Bluetooth and GPS and also for 4G LTE cellular communications. LTE (Long Term Evolution) is a $4 \mathrm{G}$ mobile communication standard helps to download our data at a faster rate. Now-a-days, 5G applications are also available. The parasitic patches can be used to obtain better bandwidth characteristics overcoming the disadvantages of microstrip patch antenna [3]. Complex patches are used to make the radiation most efficient. Elliptical shaped patches can be introduced to make the design simple and this can be optimized to get a wider bandwidth [4].

\section{PROPOSED METHOD}

The bandwidth is one of the important parameters which are to be considered in antenna design. But, a microstrip patch antenna provides a narrow bandwidth which is a major drawback. To improve the bandwidth of antenna we can,

\section{- Increase the substrate height \\ - Use low dielectric constant \\ - Creating slots on the patch Complex design patterns}

In this project, the bandwidth is increased using partial ground, changing the position of the feed line, using a curved slot on the patch, and using parasitic patches.

\section{A. Equations for designing an antenna}

A microstrip patch antenna along with its dimensions is shown in Fig.1. 


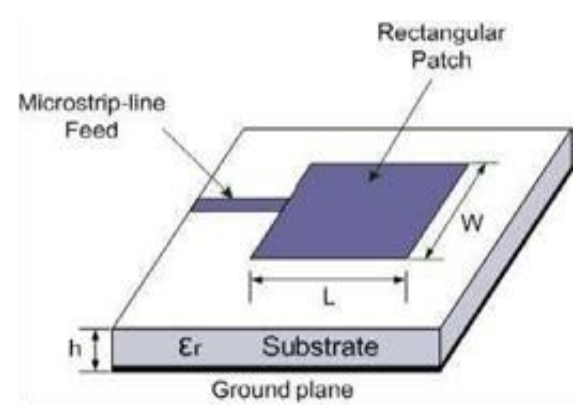

Fig.1 Microstrip patch antenna

The steps involved in designing an antenna include five steps. They are shown below.

Step 1-Width Calculation (W):

The width of the microstrip patch antenna is given by,

$$
W=\frac{c}{2 f_{0} \sqrt{\frac{\left(\varepsilon_{r}+1\right)}{2}}}
$$

where, $r$ - Dielectric constant of the substrate

$\mathrm{h}-$ Height of the dielectric

W - Width of the patch

Step 2-Effective dielectric constant $\left(\varepsilon_{\text {reff }}\right)$ :

$$
\varepsilon_{\text {reff }}=\frac{\varepsilon_{r}+1}{2}+\frac{\varepsilon_{r}-1}{2}\left[1+12 \frac{h}{W}\right]^{\frac{-1}{2}}
$$

Step 3-Effective length ( $\left.\mathrm{L}_{\text {eff }}\right)$ :

$$
\mathbf{L}_{\text {eff }}=\frac{c}{2 f_{0} \sqrt{\varepsilon_{\text {reff }}}}
$$

where, $\mathrm{c}-$ Speed of light $\left(3 \times 10^{8} \mathrm{~m} / \mathrm{s}\right)$

$\mathrm{f}-$ Resonant frequency

Step 4-Calculation of change in length $(\Delta \mathrm{L})$ :

$$
\Delta L=0.412 h \frac{\left(\varepsilon_{\text {reff }}+0.3\right)\left(\frac{W}{h}+0.264\right)}{\left(\varepsilon_{\text {reff }}-0.258\right)\left(\frac{W}{h}+0.8\right)}
$$

Step 5-Length Calculation (L):

$$
\mathbf{L}=\mathbf{L}_{\text {eff }}-2 \Delta \mathbf{L}
$$

\section{B. Modelling and Design}

From the design formulae, the length and width of the patch is calculated and further the antenna is designed in the software by making some changes in the ground plane, feed line and also the shape of the patch and the slot in order to obtain increased bandwidth characteristics. Table. 1 describes the measurements for the designed antenna.
Table.1 Antenna measurements

\begin{tabular}{|l|l|}
\hline Substrate Material & FR4 (Flame Retardant 4) \\
\hline Substrate Height & $\mathbf{1 . 6 m m}$ \\
\hline Substrate Dimension & $\mathbf{5 5 ~} \mathbf{~ m m ~} \mathbf{~ 5 0 ~} \mathbf{~ m m ~ x ~ 1 . 6 m m ~}$ \\
\hline Length of the feed line & $\mathbf{2 0 m m}$ \\
\hline Width of the feed line & $\mathbf{2 . 5 m m}$ \\
\hline Dielectric constant & $\mathbf{4 . 4}$ \\
\hline Operating frequency & $\mathbf{8 . 6 G H z}$ \\
\hline Length of patch & $\mathbf{7 . 6 3 m m}$ \\
\hline Width of patch & $\mathbf{1 0 . 6 2} \mathbf{m m}$ \\
\hline
\end{tabular}

In this project, three types of antenna design are introduced to obtain wide-band. The schematic model design of the top view (a) and bottom view (b) for these three proposed antenna are shown in Fig.2, Fig.3, and Fig.4.

- Proposed Model I(Curved Patch with curved slot)

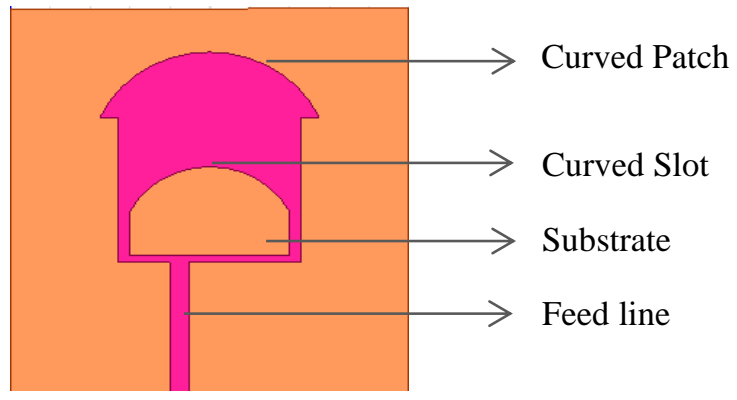

(a)

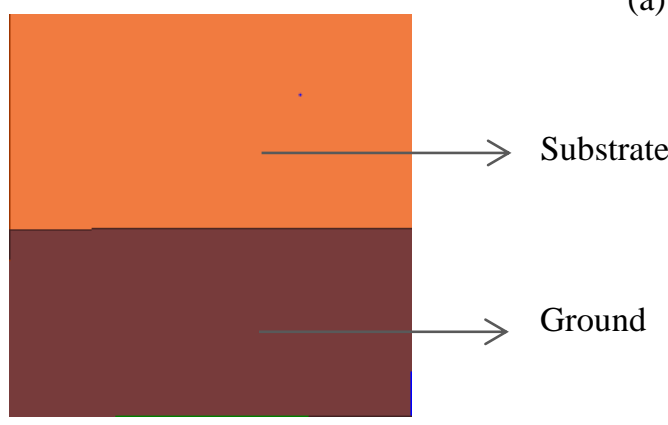

(b)

Fig.2 Proposed antenna design Model-1

- $\quad$ Proposed Model II (Parasitic patch with curved slot)

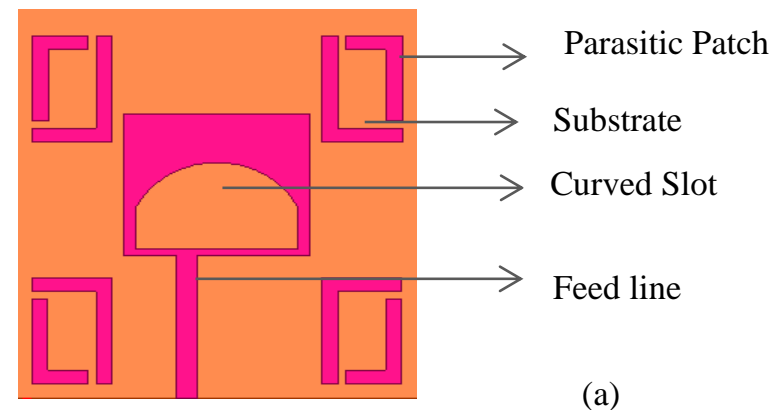

(a) 


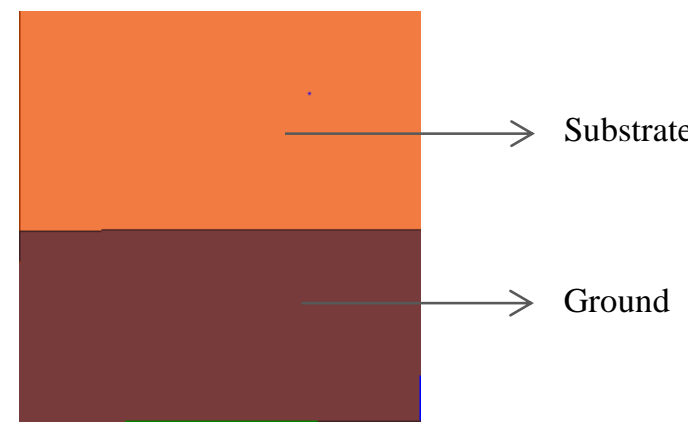

(b)

Fig.3 Proposed antenna design Model-2

- $\quad$ Proposed Model III (Parasitic patch and curved patch with curved slot)

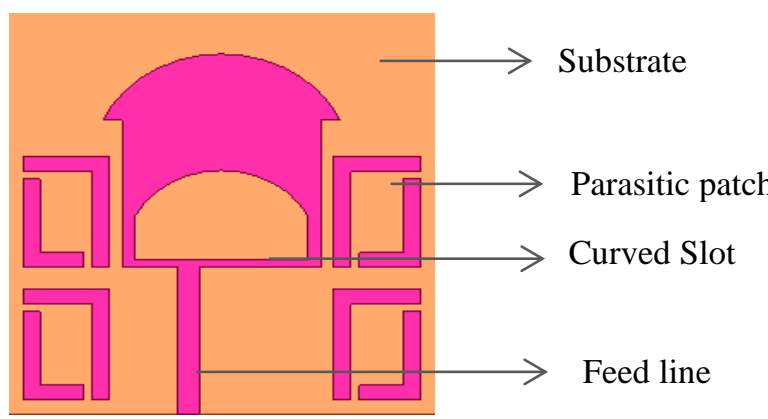

(a)

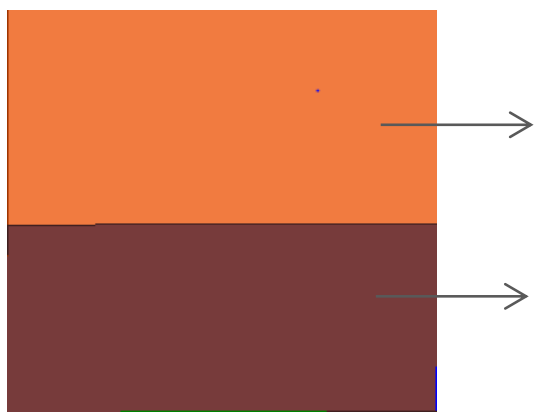

Substrate

(b)

Fig.4 Proposed antenna design Model-3

III. SOFTWARE AND HARDWARE REQUIREMENTS

Generally to design an antenna, we need software. In this project, the antenna is designed and simulated using the HFSS software. After designing the antenna, fabrication process is done. Later on the fabricated antenna is tested by a test system. Here, Vector Network Analyser (VNA) is used for testing the antenna.

ANSYS HFSS (High Frequency Structure Simulator) is simulation software for designing and simulating highfrequency electronic products. The optimization tool available with HFSS is very useful for antenna engineers to optimize the antenna parameters very accurately. For boundary schemes, Radiation and Perfect-E boundaries are widely used for this design. In this project, HFSS is used to design an antenna which should satisfy increased bandwidth suitable for many applications.

The steps involved in designing the antenna and simulation procedure is mentioned in the following flowchart (Fig.5).

Draw substrate, ground and patch

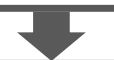

Draw feed and line from feed to ground

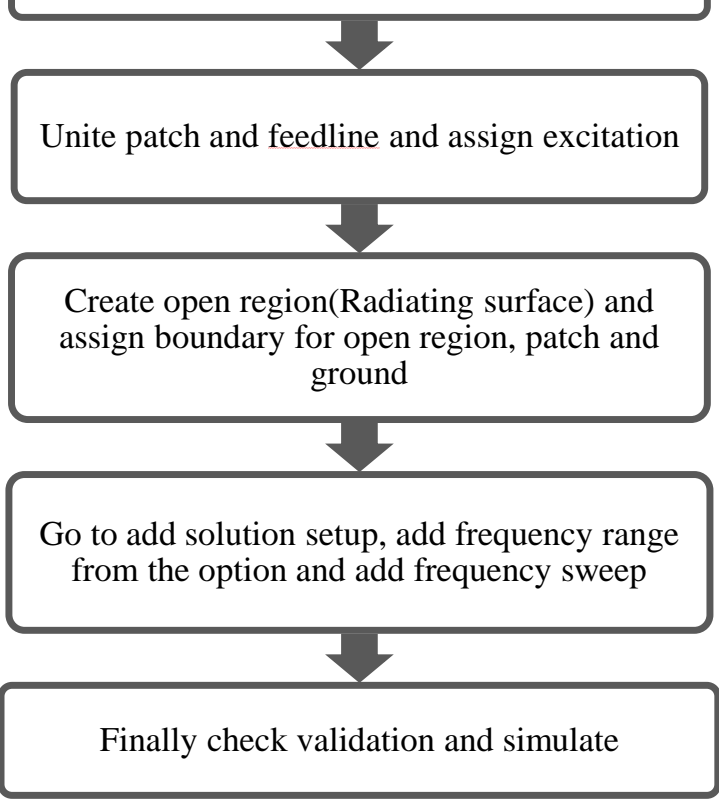

Fig.5 Steps involved in designing an antenna

\section{RESULTS AND DISCUSSION}

\section{A. Bandwidth Calculation:}

The bandwidth can be calculated as the difference between the higher cut-off frequency $\left(\mathrm{f}_{\mathrm{H}}\right)$ and lower cut-off frequency $\left(f_{L}\right)$. It is given by,

\section{Bandwidth $=\mathbf{f}_{H}-\mathbf{f}_{L}$}

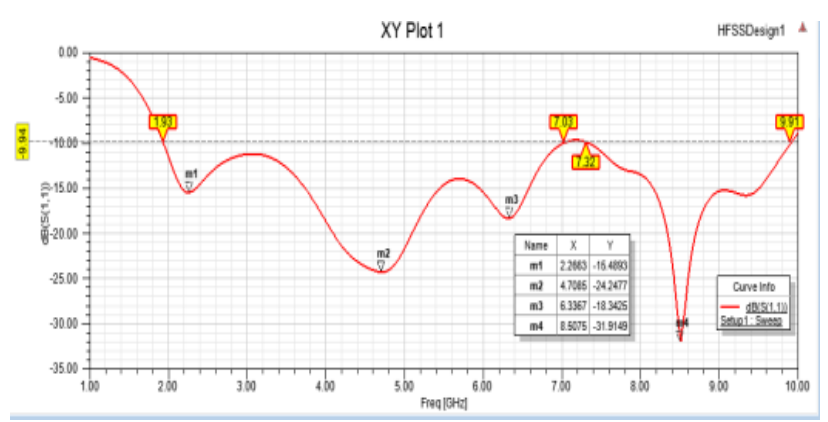

Fig.6 Return loss for the proposed antenna(Model-1) 
From the Fig.6, the bandwidth is calculated using, $\mathrm{f}_{\mathrm{H}}=$ $7.03 \mathrm{GHz}$ and $\mathrm{f}_{\mathrm{L}}=1.93 \mathrm{GHz}$ and critical frequency $8.6 \mathrm{GHz}$. Thus, the bandwidth obtained is $5.1 \mathrm{GHz}$. The percentage of the bandwidth is obtained as $((5.1 / 8.6) \times 100)$ i.e. $59.3 \%$. Hence, the fractional bandwidth for the antenna is $59.3 \%$.

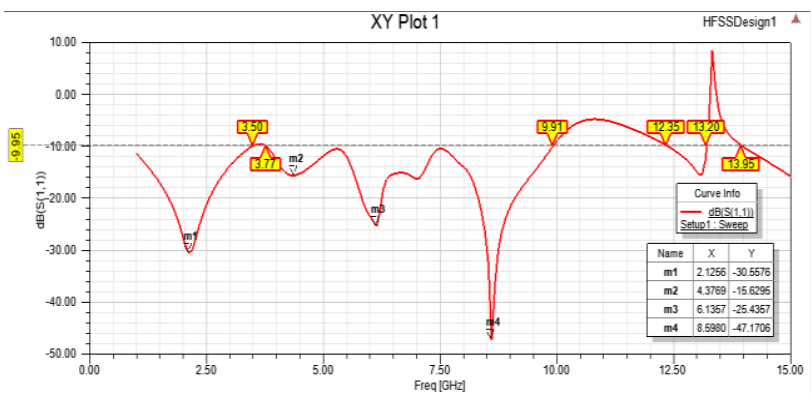

Fig.7 Return loss for the proposed antenna(Model-2)

In the Fig.7, we have $f_{H}=9.91 \mathrm{GHz}, \mathrm{f}_{\mathrm{L}}=3.77 \mathrm{GHz}$ and $\mathrm{f}_{\mathrm{C}}=8.6 \mathrm{GHz}$. Thus, the bandwidth can be calculates as $(9.63-3.67=6.41 \mathrm{GHz})$ and the percentage of the bandwidth is obtained as $((5.96 / 8.6) \times 100)$ i.e. $71.39 \%$. Thus, the impedance bandwidth is $71.39 \%$.

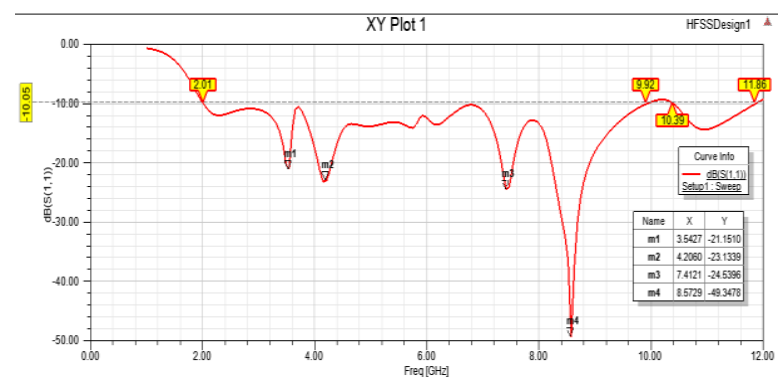

Fig.8 Return loss for the proposed antenna(Model-3)

From the Fig. $8, \mathrm{f}_{\mathrm{H}}=9.92 \mathrm{GHz}$ and $\mathrm{f}_{\mathrm{L}}=2.01 \mathrm{GHz}$ and $\mathrm{f}_{\mathrm{C}}=8.6 \mathrm{GHz}$. Thus, the bandwidth can be calculates as $(9.63-2.02=7.91 \mathrm{GHz})$ and the percentage of the bandwidth is obtained as $((7.61 / 8.6) \times 100)$ i.e. $91.97 \%$. Hence, the fractional bandwidth for the antenna is achieved as $91.97 \%$.

The Fig.6, Fig.7, and Fig.8 show the return loss plot for the desired proposed antenna for the Model-1, Model-2, and Model-3 respectively

\section{B. Radiation Pattern:}

The radiation pattern of microstrip patch antenna is broad. It has a low radiated power and bandwidth is narrow. It has lesser directivity. Fig. 9 shows the desired radiation pattern for the proposed antenna for Model-1 design. Here, at 2.26 $\mathrm{GHz}$, the radiation pattern is wider when compared to other frequencies. Fig.10 shows the pattern for the Model-2 design where, it is wider at $8.59 \mathrm{GHz}$. The radiation pattern for Model-3 design shows a wider range at $8.57 \mathrm{GHz}$ and it is shown in Fig. 11
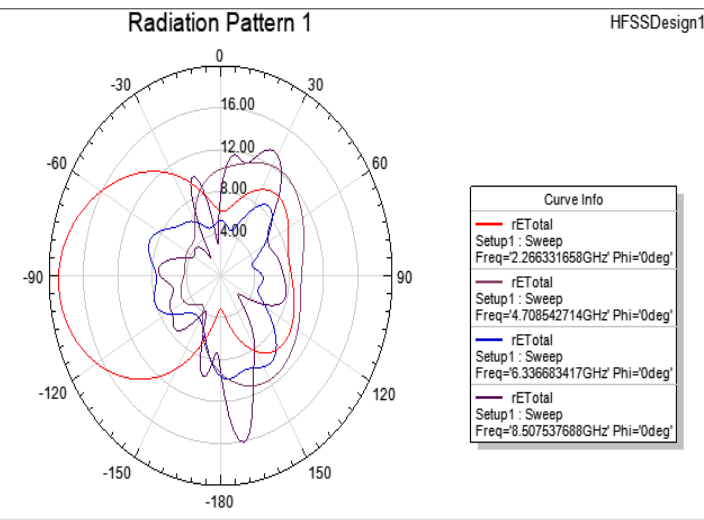

Fig.9 Radiation pattern for the proposed antenna (Model-1)

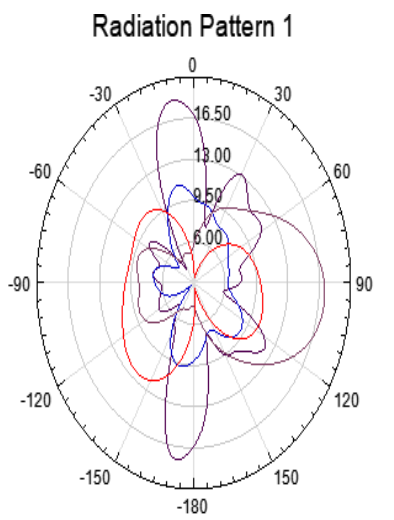

HFSSDesign1

Fig.10 Radiation pattern for the proposed antenna(Model-2)
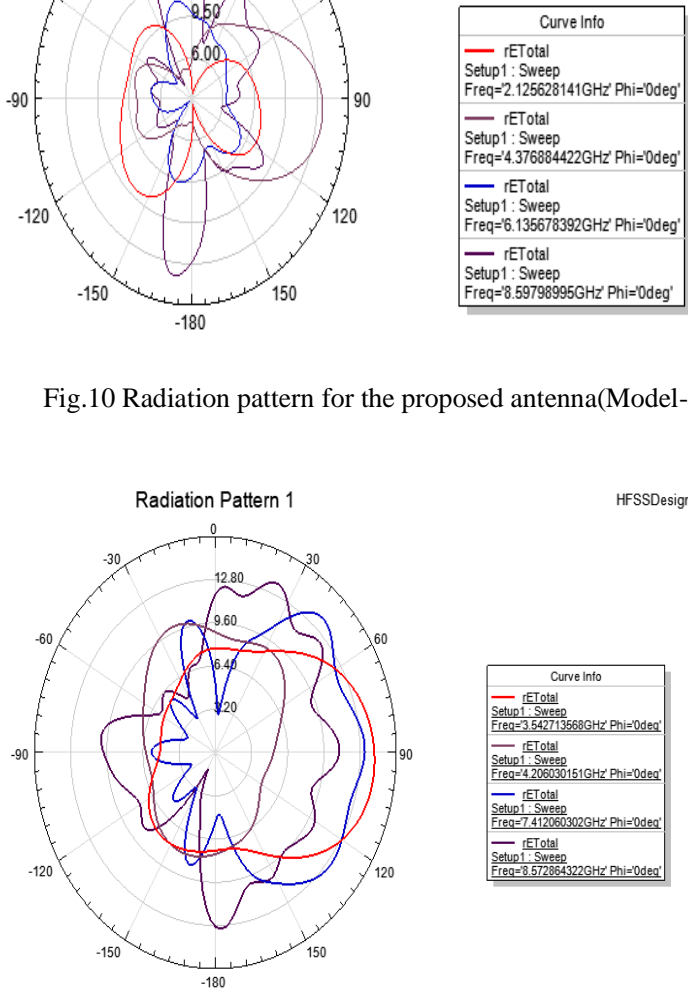

Fig.11 Radiation pattern for the proposed antenna(Model-3)

\section{VSWR:}

VSWR stands for Voltage Standing Wave Ratio. It is related to the reflection coefficient of an antenna, which describes how much power is reflected from the antenna. In terms of VSWR, a good antenna should satisfy the condition $(1<$ VSWR < 2). The VSWR for the proposed antenna for Model-1 design is shown in Fig.12, Model-2 design in Fig.13, and Fig.14 shows the VSWR plot for the Model-3 design. 


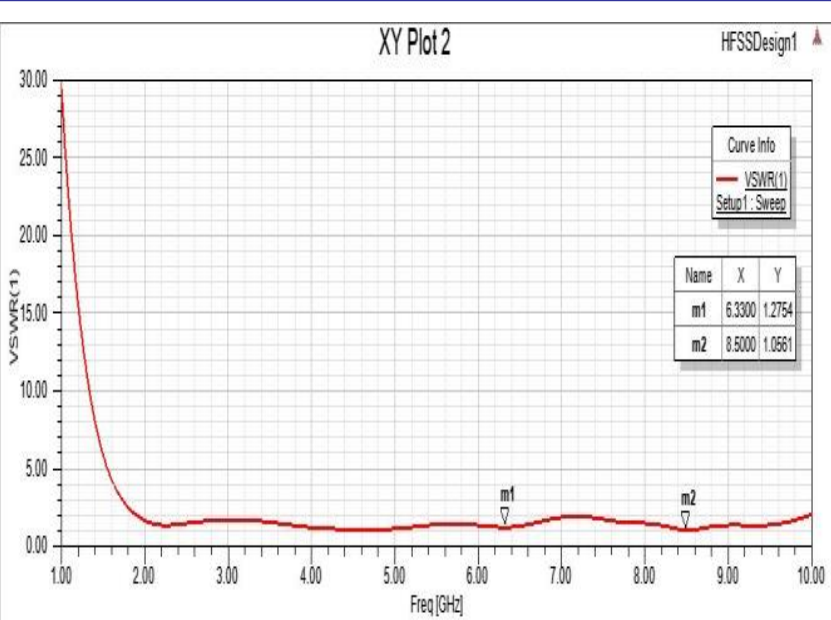

Fig.12 VSWR for the proposed antenna(Model-1)

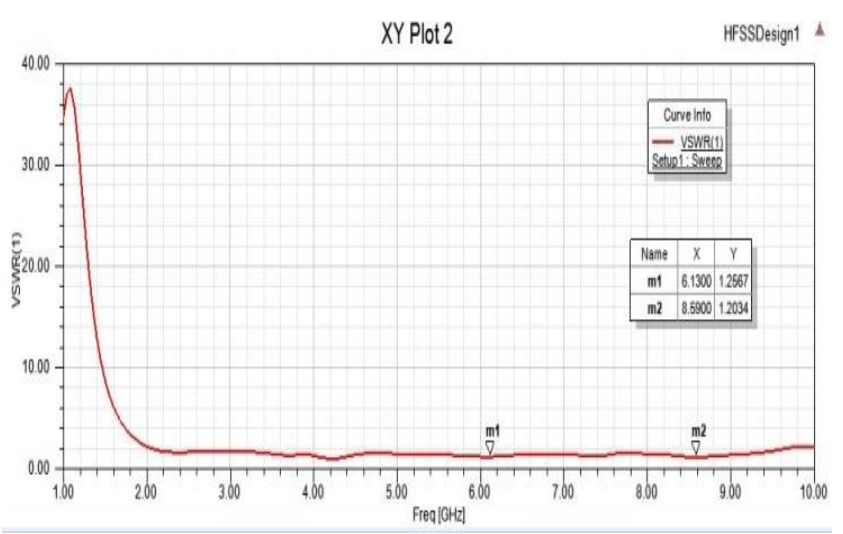

Fig.13 VSWR for the proposed antenna(Model-2)

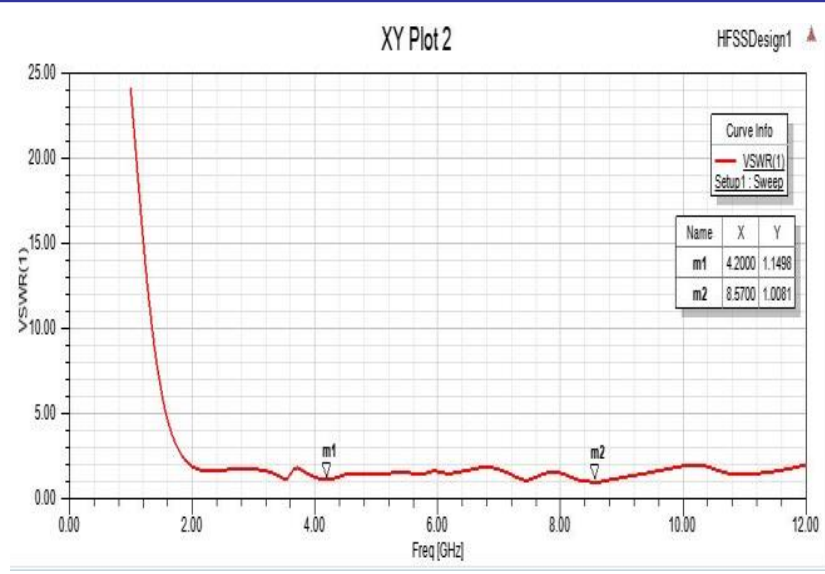

Fig.14 VSWR for the proposed antenna(Model-3)

D. Gain:

The gain can be defined as the ratio of maximum power received from the given antenna to the maximum power received from the reference antenna. From the gain obtained, it is clear that the power radiated by an antenna is concentrated at one direction and minimum at other directions.

The antenna parameters for the three proposed model are obtained as shown in Fig.14, Fig.15 and Fig.16 respectively. For the proposed antenna (Model 3), the bandwidth is found to be $7.91 \mathrm{GHz}$. It offers a wide impedance bandwidth of 91.97\% (covering from 2.01 to $9.92 \mathrm{GHz}$ at $\mathrm{VSWR} \leq 2$ ), symmetric radiation pattern, and a high gain of $6.8 \mathrm{~dB}$ at 7.4 $\mathrm{GHz}(\mathrm{C}$-band) and $4.58 \mathrm{~dB}$ at $8.6 \mathrm{GHz}(\mathrm{X}$-band). The Model-2 proposed antenna provides a bandwidth $6.41 \mathrm{GHz}$ and a gain of $5.67 \mathrm{~dB}$ at $8.6 \mathrm{GHz}$.

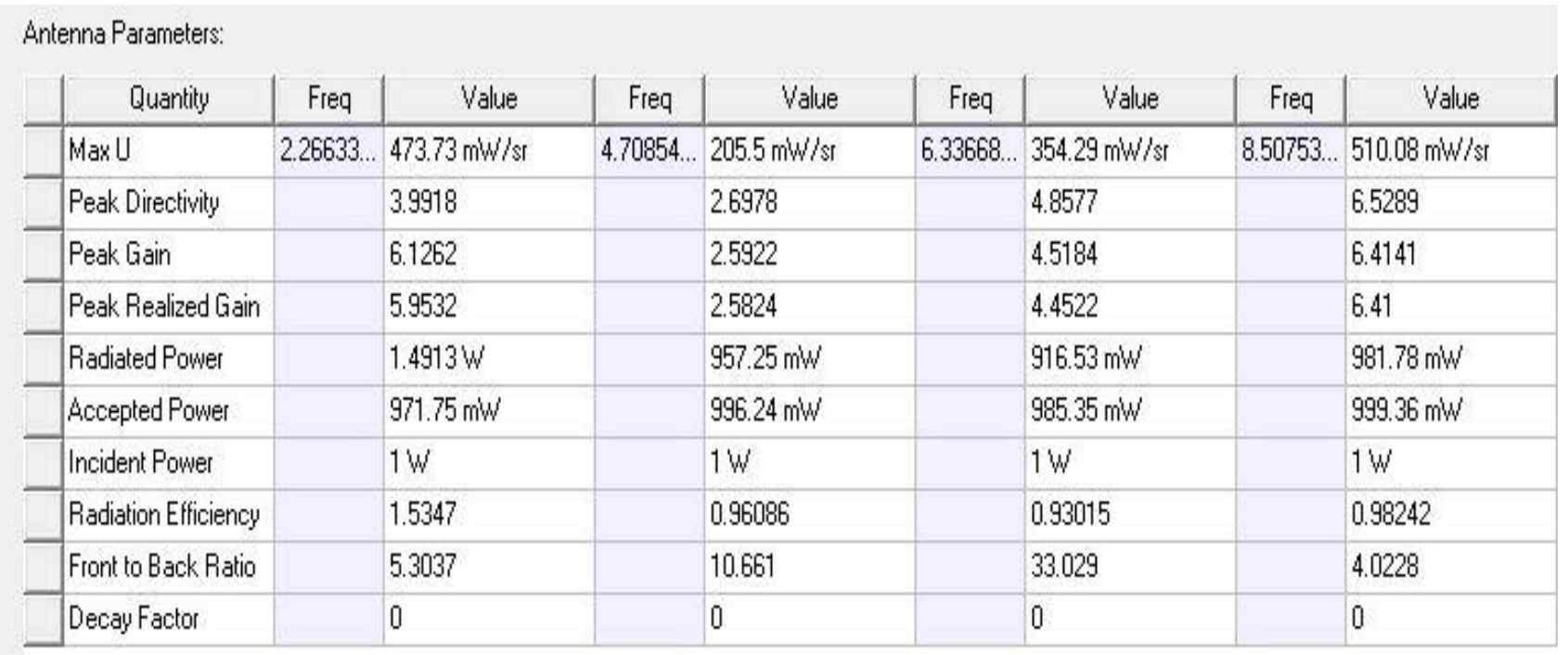

Fig.15 Antenna parameters for the proposed antenna(Model-1) 


\begin{tabular}{|c|c|c|c|c|c|c|c|c|}
\hline Quantity & Freq & Value & Freq & Value & Freq & Value & Freq & Value \\
\hline Max U & $2.12562 \ldots$ & $254.99 \mathrm{~mW} / \mathrm{si}$ & $4.37688 \ldots$ & $459.31 \mathrm{~mW} / \mathrm{sr}$ & $6.13567 \ldots$ & $199.94 \mathrm{~mW} / \mathrm{sr}$ & $8.59798 \ldots$ & $451.76 \mathrm{~mW} / \mathrm{sr}$ \\
\hline Peak Directivity & & 2.2024 & & 5.9788 & & 3.0487 & & 6.7403 \\
\hline Peak Gain & & 3.2072 & & 5.9344 & & 2.5198 & & 5.6772 \\
\hline Peak Realized Gain & & 3.2044 & & 5.772 & & 2.5126 & & 5.6771 \\
\hline Radiated Power & & $1.4549 W$ & & $965.42 \mathrm{~mW}$ & & $824.14 \mathrm{~mW}$ & & $842.27 \mathrm{~mW}$ \\
\hline Accepted Power & & $999.12 \mathrm{~mW}$ & & $972.64 \mathrm{~mW}$ & & $997.14 \mathrm{~mW}$ & & $999.98 \mathrm{~mW}$ \\
\hline Incident Power & & $1 W$ & & $1 W$ & & $1 W$ & & $1 W$ \\
\hline Radiation Efficiency & & 1.4562 & & 0.99257 & & 0.8265 & & 0.84228 \\
\hline Front to Back Ratio & & 6.3308 & & 7.759 & & 4.00084 & & 1.5187 \\
\hline Decay Factor & & 0 & & 0 & & 0 & & 0 \\
\hline
\end{tabular}

Fig.15 Antenna parameters for the proposed antenna(Model-2)

\begin{tabular}{|c|c|c|c|c|c|c|c|c|}
\hline \multicolumn{9}{|l|}{ Antenna Parameters: } \\
\hline Quantity & Freq & Value & Freq & Value & Freq & Value & Freq & Value \\
\hline Max U & $3.54271 \ldots$ & $400.85 \mathrm{~mW} / \mathrm{sr}$ & $4.20603 \ldots$ & $238.61 \mathrm{~mW} / \mathrm{sr}$ & $7.41206 \ldots$ & $539.4 \mathrm{~mW} / \mathrm{sr}$ & $8.57286 \ldots$ & $364.9 \mathrm{~mW} / \mathrm{sr}$ \\
\hline Peak Directivity & & 5.5498 & & 3.2177 & & 7.8611 & & 5.6927 \\
\hline Peak Gain & & 5.0762 & & 3.0132 & & 6.8023 & & 4.5856 \\
\hline Peak Realized Gain & & 5.0373 & & 2.9986 & & 6.7784 & & 4.5856 \\
\hline Radiated Power & & $907.65 \mathrm{~mW}$ & & $931.91 \mathrm{~mW}$ & & $862.27 \mathrm{~mW}$ & & $805.51 \mathrm{~mW}$ \\
\hline Accepted Power & & $992.33 \mathrm{~mW}$ & & $995.14 \mathrm{~mW}$ & & $996.48 \mathrm{~mW}$ & & $999.99 \mathrm{~mW}$ \\
\hline Incident Power & & $1 W$ & & $1 W$ & & $1 W$ & & $1 \mathrm{~W}$ \\
\hline Radiation Efficiency & & 0.91466 & & 0.93646 & & 0.86532 & & 0.80552 \\
\hline Front to Back Ratio & & 11.467 & & 3.1453 & & 38.76 & & 22.77 \\
\hline Decay Factor & & 0 & & 0 & & 0 & & 0 \\
\hline
\end{tabular}

Fig.16 Antenna parameters for the proposed antenna(Model-3)

Table. 2 Bandwidth comparison table

\begin{tabular}{|c|c|c|}
\hline & $\begin{array}{c}\text { Bandwidth } \\
\left(\mathbf{F}_{\mathrm{H}}-\mathbf{F}_{\mathrm{L}}\right)\end{array}$ & $\begin{array}{c}\text { Fractional Bandwidth } \\
\left(\text { Bandwidth / } \mathbf{F}_{\mathrm{C}}\right) \mathbf{1 0 0}\end{array}$ \\
\hline $\begin{array}{c}\text { Proposed } \\
\text { Model 1 }\end{array}$ & $5.1 \mathrm{GHz}$ & $\mathbf{5 9 . 3 \%}$ \\
\hline $\begin{array}{c}\text { Proposed } \\
\text { Model 2 }\end{array}$ & $6.41 \mathrm{GHz}$ & $\mathbf{7 1 . 3 9 \%}$ \\
\hline $\begin{array}{c}\text { Proposed } \\
\text { Model 3 }\end{array}$ & $7.61 \mathrm{GHz}$ & $\mathbf{9 1 . 9 7 \%}$ \\
\hline
\end{tabular}

Table 2 shows the bandwidth obtained by the proposed antenna for the three different models.

\section{CONCLUSION}

The proposed microstrip patch antenna is thus designed by using a curved slot and parasitic patches to obtain wide bandwidth characteristics. Additionally, the position of the feed line is also changed and the ground is made partial. The microstrip patch antenna is designed using ANSYS HFSS software and the simulated results are obtained. The return loss curve was plotted radiation pattern and the antenna parameters were obtained. From the simulated results, the proposed Model-3 antenna provides better bandwidth 
characteristics than other antennas. This antenna offers a wide impedance bandwidth of $91.97 \%$ (covering from 2.02 to 9.92 $\mathrm{GHz}$ at $\mathrm{VSWR} \leq 2$ ), symmetric radiation pattern, and provides a gain of $4.58 \mathrm{~dB}$ at $8.6 \mathrm{GHz}$. These three proposed antenna are at good assent with other works. Since it covers C-band and partially X-band, it can be used in C-band applications and some X-band applications.

\section{FUTURE SCOPE}

For further bandwidth enhancement, the design should be optimized to provide an ultra-wide bandwidth i.e. the return loss plot should be obtained as a horizontal straight line satisfying the ultra-wide range. The microstrip patch antenna can be designed using parasitic patch(es), partial ground, slot(s), and DGS(Defective Ground Structure). Parasitic patch and partial ground can help to improve the bandwidth. So with the help of such design we can get better wide bandwidth characteristics and can cover both C-band (4 to $8 \mathrm{GHz}$ ) and $\mathrm{X}$-band ( 8 to $12 \mathrm{GHz}$ ) applications.

\section{REFERENCES}

[1] Khanda Anum, Milind Saurabh Singh, Rajan Mishra, and G. S. Tripathi,"Bandwidth enhancement of a microstrip patch antenna for ultra- wideband applications", International Conference on Electrical, Electronics, Materials and AppliedScience, AIP Conference Proceedings 1952, 020053, (2018)

[2] G Manjunath, Naseeruddin and $\mathrm{K}$ M Sadyojatha, "Bandwidth Enhancement Techniques for MPA for Wideband and Multiband Applications", IEEE International Conference on Computational Intelligence and Computing Research (ICCIC), ISSN No: 2473-943X, (2017)

[3] Mekala Harinath Reddy, R.M. Joany, M. Jayasaichandra Reddy, M. Sugadev and E. Logashanmugam, "Bandwidth enhancement of microstrip patch antenna using parasitic patch", IEEE International Conference on Smart Technologies and Management for Computing, Communication, Controls, Energy and Materials (ICSTM), pp.295 298, (2017)

[4] Tale Saeidi, Idris Ismail,Wong Peng Wen, Adam R.H.Alhawari and Ahmad Mohammadi, "Ultra-Wideband Antennas for Wireless Communication Applications", International Journal of Antenna and propagation, (2019)

[5] Rahul Mondal, P. Soni Reddy, Debasree Chanda Sarkar and Partha Pratim Sarkar, "Compact ultra-wideband antenna: improvement of gain and FBR across the entire bandwidth using FSS", IET Microwaves, Antennas \& Propagation, Volume: 14 , Issue: 1 , pp: 66- 74, (2020)

[6] Amr H. Hussein, Haythem Hussein Abdullah, Mahmoud Ahmed Attia, And Alaa Mohamed Abada, "S-Band Compact Microstrip Full-Duplex Tx/Rx Patch Antenna With High Isolation", IEEE Antennas and Wireless Propagation Letters, Volume: 18, Issue: 10,ISSN No:1548 5757,pp: 2090-2094,(2019)

[7] May Abo El-Hassan, Khalid Fawzy A. Hussein and Kamal H. Awadalla, "Microstrip antenna with L-shaped slots for circularly polarised satellite applications", IET-The Journal of Engineering, Volume: 2019 , Issue: 12 , pp:8428 - 8431, (2019)

[8] Wang Youcheng, Yang Yanjiao, Chi Qingxi and Pei Hucheng, "Design of a compact ultra-wideband MIMO antenna", IET-The Journal of Engineering, Volume: 2019, Issue: 20 , pp: 6487 - 6489, (2019)

[9] Ming Min and Lu Guo, "Design of a Wideband Single-Layer Reflectarray Antenna Using Slotted Rectangular Patch With Concave
Arms", IEEE Access, Volume:7, ISSN No: 2169 - 3536, pp: 176197 176203, (2019)

[10] Hidayat Ullah and Farooq A. Tahir, "Broadband planar antenna array for future 5G communication standards" IET Microwaves, Antennas \& Propagation, Volume: 13 , Issue: 15 , pp: 2661 - 2668, (2019)

[11] Min-Sung Kim and Sung-Soo Kim, "Design and Fabrication of 77-GHz Radar Absorbing Materials Using Frequency-Selective Surfaces for Autonomous Vehicles Application", IEEE Microwave and Wireless Components Letters, Volume: 29 , Issue: 12 , pp: 779 - 782, (2019)

[12] Qing Liu, Dong-Fang Zhou, Dei-Wei Zhang, Da-Long Lu and Yi Zhang, "Dual-Mode Microstrip Patch Bandpass Filters With Generalized Frequency Responses", IEEE Access, Volume: 7, ISSN No: 2169 - 3536, pp: 163537 - 163546, (2019)

[13] Nouman Rasool, Huang Kama, Muhammad Abdul Basit and Mujeeb Abdullah, "A Low Profile High Gain Ultra Lightweight Circularly Polarized Annular Ring Slot Antenna for Airborne and Airship Applications", IEEE Access, Volume: 7, ISSN No: 2169 - 3536, pp: 155048 - 155056, (2019)

[14] Guru Prasad Mishra and Biswa Binayak Mangaraj, "Miniaturised microstrip patch design based on highly capacitive defected ground structure with fractal boundary for X-band microwave communications", IET Microwaves, Antennas \& Propagation, Volume: 13 , Issue: 10, pp: 1593 - 1601, (2019)

[15] Xiongwen Zhao and Sharjeel Riaz, "A Dual-Band Frequency Reconfigurable MIMO Patch-Slot Antenna Based on Reconfigurable Microstrip Feedline", IEEE Access, Volume: 6, ISSN No: 2169 - 3536, pp: 41450 - 41457, (2018)

[16] Inderpreet Kaur, Anil Kumar Singh,Jagriti Makhija, Sakshi Gupta and Krishna Kumar Singh, "Designing and Analysis of Microstrip Patch Antenna For UWB Applications", IEEE, 3rd International Conference On Internet of Things: Smart Innovation and Usages (IoT-SIU), (2018)

[17] Tahsin Ferdous Ara Nayna, Feroz Ahmed and Emranul Haque, "Bandwidth enhancement of a rectangular patch antenna in X band by introducing diamond shaped slot and ring in patch and defected ground structure", IEEE International Conference on Wireless Communications, Signal Processing and Networking (WiSPNET), ISBN No: 978-1-5090-4442-9, pp:2512 - 2516, (2017)

[18] ] K. Anusudha and M. Karmugil, "Design of circular microstip patch antenna for ultra wide band applications", IEEE International Conference on Control, Instrumentation, Communication and Computational Technologies (ICCICCT), pp.304-308, (2016) 